\title{
DIÁLOGOS PERTINENTES ACERCA DA UTILIZAÇÃO DE RECURSOS EDUCACIONAIS ABERTOS PARA A EDUCAÇÃO
}

\section{RELEVANT DIALOGUES ABOUT THE UTILIZATION OF EDUCATIONAL RESOURCES OPEN TO EDUCATION}

\section{DIÁLOGOS PERTINENTES ACERCA DE LA UTILIZACIÓN DE RECURSOS EDUCACIONALES ABIERTOS PARA LA EDUCACIÓN}

Anamelea de Campos Pinto ${ }^{1}$ Júlio César Correia da Silva ${ }^{2}$ Luis Paulo Mercado ${ }^{3}$

RESUMO: A crescente profusão e difusão das tecnologias digitais de informação e comunicação (TDIC) possibilitaram a criação de novas práticas de ensino que incorporam a utilização de recursos multimidiáticos como facilitadores do processo de ensino e aprendizagem dos sujeitos conectados. Nesse sentido, os Recursos Educacionais Abertos (REA) surgem como uma proposta inovadora para o campo da educação e tem como objetivo constituir autores digitais mais responsáveis na edificação

Submetido em: 13/10/2018 - Aceito em: 18/11/2018 - Publicado em: 26/01/2019

\footnotetext{
${ }^{1}$ Doutora na área da Educação, mais especificamente na modalidade de Educação a Distância. Atualmente é professora do Centro de Educação, da Universidade Federal de Alagoas, atuando no Programa de Pós-Graduação em Educação Brasileira, na linha de pesquisa Tecnologias da Informação e Comunicação na Educação e no Programa de PósGraduação em Ensino de Ciências e Matemática. Tem experiência em planejamento, concepção, implementação e avaliação de ações na modalidade a distância, além de coordenar e orientar núcleos de pesquisa e gerenciar grupos de trabalho. Atuou como coordenadora do Núcleo de Comunicação e Produção de Materiais Didáticos, na Coordenadoria Institucional de Educação a Distância, no período de dez/2011 a dez/2012. Durante os anos de 2006 a 2011 foi coordenadora da CIED e representou a UFAL junto ao Sistema Universidade Aberta do Brasil (UAB). No biênio 2012 2014 atuou como vice-coordenadora do Programa de Pós-Graduação em Ensino de Ciências e Matemática da UFAL, sendo reeleita para o biênio 2014-2016. No período de 2016-2017 realizou uma capacitação na Universidade Aberta de Portugal sobre a temática de Recursos Educacionais Abertos e em 2017-2018 um pós doutoramento na Université de Poitiers- França.

2 Pedagogo formado Universidade Federal de Alagoas (UFAL). Estagiário na Secretaria Municipal de Educação (SEMED). Pesquisador Júnior na área de Educação, com ênfase nas temáticas de: Tecnologias Digitais de Informação e Comunicação (TDIC), Educação Aberta (EA), Recursos Educacionais Abertos (REA) e Educação à Distância (EaD).

${ }^{3}$ Doutor em Educação (PUC/SP, 1998), Mestre em Educação (UFSM, 1993), Especialista em Formação de Professores em Mídias na Educação (UFAL, 2010), Graduado em Ciências Biológicas Licenciatura Plena (UFSM, 1989). Realizou aperfeiçoamento em Formação em Tutoria Online pela Organização dos Estados Americanos (OEA/INEAM) e em Melhoria da Qualidade da Educação pela UNESCO (UNESCO/OEA). É Professor Associado III vinculado ao Programa de Pós-Graduação em Educação da Universidade Federal de Alagoas. Lider do Grupo de Pesquisa Tecnologias da Informação e Comunicação na Formação de Professores Presencial e Online.
} 


\section{Revista Docência e Cibercultura}

e partilha do conhecimento, possibilitando a engendração do conceito de abertura e liberdade face as especificidades do licenciamento em Creative Commons e as etapas de produção e execução dos REA. Para nortear a construção do artigo, que se caracteriza como uma pesquisa teórica acerca do usabilidade de REA, buscou-se em Silva et al (2017), Amiel (2012), Pesce (2013), Santana et al (2012) e Litto e Mattar (2017) respostas para solucionar tais problemáticas: Quais elementos são essenciais para a construção e usabilidade dos REA? De que forma podemos propor a usabilidade desses recursos para a educação? Desse modo descobriu-se que o alicerce deste artigo está na forma de investigar e consultar a importância do uso dos REA como uma política pública educacional, sobretudo na proposta epistemológica da Teoria Conectivista e nas contribuições históricas da Educação Aberta pela qual a (co)produção e a (co)aprendizagem dos REA se apoia. Como resultado, apresentamos a proposição de alguns elementos norteadores da construção, execução e utilização dos REA, promovendo diálogos pertinentes para a preparação de um guia de recomendações de usabilidade, abordando conteúdos introdutórios acerca da temática em tela e propondo como um dos elementos a formatação de uma plataforma online híbrida, que denominamos de restart, para organizar e contabilizar obras em REA ou transformadas em Domínio Público, complementando as cinco liberdades essenciais para a condução dos REA, que são: revisar, reutilizar, remixar e redistribuir. A finalidade desse estudo é discutir as formas de licenciamento em Creative Commons, o acesso aos recursos, um método de trabalho que leve em consideração a saúde, bem-estar e segurança dos usuários e produtores de REA e assegurar uma avaliação aberta na concepção dos REA, trazendo tais peculiaridades como componentes do guia, que estejam em conformidade com as suas bases legais-normatizadoras.

PALAVRAS-CHAVE: Usabilidade; REA; Guia de recomendações.

\section{INTRODUÇÃO}

Nesse artigo pesquisamos sobre a utilização dos REA, que configuram-se como ferramentas de interação e colaboração que podem auxiliar professores e estudantes no seu processo de ensino e aprendizagem, sobretudo na partilha do conhecimento que ocorre no intercâmbio de experiências entre os agentes escolares e os recursos digitais pelos quais se conectam (SILVA et al, 2017, p. 2). Prezamos por uma educação livre para todos os públicos (crianças, jovens, adultos e idosos) e a promoção da aprendizagem por meio da disponibilidade de recursos abertos e gratuitos, que podem ser usados, reutilizados, remixados e compartilhados por outros (AMIEL, 2012, p. 25).

De acordo com Prensky (2001, p. 1), os estudantes da atualidade são de uma geração que cresceu juntamente com a tecnologia, portanto estão familiarizados como se fossem feitos do mesmo 


\section{Revista Docência e Cibercultura}

"material". Neste novo cenário educacional professores e estudantes surgem como autores do conhecimento e podem fazer uso de qualquer ferramenta digital, desde que seja utilizada para fins pedagógicos. Mas o que diferenciam os REA de outras propostas é o seu caráter colaborativo, que se caracteriza na sua construção como materiais educacionais abertos, disponibilizados em plataformas online e licenciados em Creative Commons - https://br.creativecommons.org/licencas/ - ou em domínio público, que facilitam o acesso e busca para que estudantes e professores façam a utilização do mesmo sem nenhum custo benefício. Outra característica dos REA é não estar totalmente voltado para fins comerciais, pois segundo Santana et al (2012, p. 30) "os REA podem incluir cursos completos, partes de cursos, módulos, livros didáticos, artigos de pesquisa, vídeos, testes, softwares, e qualquer outra ferramenta, material ou técnica, que possa apoiar o acesso e a produção de conhecimento."

Nessa perspectiva, buscou-se a compreensão dos conceitos referentes à utilização de REA em Pesce (2013), que discute o potencial destes na interação de professores e estudantes inseridos no mundo virtual e a partilha do conhecimento que promove a (co)produção e a (co)aprendizagem dos estudantes como autores digitais na escola, face as intervenções do professor, como também os conceitos apresentados por Silva et al (2017), Amiel (2012), Santana et al (2012) e Litto e Mattar (2017) que trazem conteúdos acerca das especificidades do licenciamento dos REA e as suas vantagens para o ensino aberto online, que fez com que nos questionássemos sobre os elementos essenciais para a construção e usabilidade dos REA e a proposição do uso desses recursos para a educação.

Com base nos estudos sobre a temática em tela, apresentamos como referencial teórico as premissas da Educação Aberta na visão de Santos (2012) e da Teoria Conectivista proposta por Siemens (2005) e Downes (2008), pois estas consistem em averiguar o processo de aprendizagem que ocorre fora dos indivíduos, mais precisamente na sua interação com outros sujeitos e dentro das instituições, como por exemplo o mecanismo de consulta aos bancos de dados e a educação a distância (EAD), e também apresentar considerações acerca da usabilidade de REA como política pública para a educação. Com isso indicamos a proposição de alguns elementos pertinentes ao uso dos REA, apresentando elementos norteadores para a construção de um guia de recomendações que capte as dimensões: (a) da estética; (b) do conhecimento; (c) do ambiente e (d) das relações humanas na elaboração e manuseio desses recursos, promovendo a sua abertura e gratuidade. 


\section{Revista Docência e Cibercultura}

Inicialmente, percebemos que a finalização de um guia de recomendação está em considerar as contribuições externas de pesquisadores de outras áreas do conhecimento, sobretudo na forma de acesso e aplicabilidade desses recursos abertos na educação, como uma prática institucional. Por outro lado, em se tratando de uma pesquisa teórica, também podemos compreender a importância da utilização dos REA como política pública para a educação, pois sua construção se dá de forma democrática, participativa e colaborativa, podendo propiciar a troca de experiências entre os agentes escolares e os recursos pelos quais se conectam.

Outro ponto significativo da pesquisa é a análise dos recursos digitais facilitadores (Trello, Instagram, Facebook, Twitter, Gmail e Outlook) que podem ajudar na organização, construção e publicidade dos dados referentes a produção dos REA, contendo à Ergonomia como método de trabalho que preza pela saúde, bem-estar e segurança dos produtores e usuários de REA e a proposta de uma sexta liberdade, que denominamos de restart, que visa fomentar o espaço virtual de uma plataforma online híbrida para inserção do guia de recomendações, via infográficos instrucionais, e contabilização dos recursos abertos licenciados em Creative Commons a serem disponibilizados por área do conhecimento e tipologia do material apresentado.

Tais fatores foram trabalhados no construto científico deste artigo, delineando uma pesquisa bibliográfica com e sobre REA, na qual, a partir da elaboração das problemáticas em tela evidenciamos uma investigação teórica acerca do uso e das especificidades dos REA, visando a compreensão sobre dados conectados e a partilha dos conteúdos inseridos no ciberespaço por meio da interação entre os agentes escolares e os respectivos recursos digitais.

Com isso, buscamos estimular a (co)produção e a (co)aprendizagem dos REA na interação dos sujeitos conectados, apresentando a proposição de alguns componentes norteadores da construção e uso dos REA, incorporando conteúdos introdutórios para o preparo de um guia de recomendações, que traz em seu bojo as formas de licenciamento e acesso, a metodologia de criação e execução e uma avaliação aberta para validar os resultados da usabilidade dos REA.

\section{POLÍTICAS PÚBLICAS PARA A UTILIZAÇÃO DOS REA}

Do ponto de vista político-democrático-pedagógico, REA também pode ser entendido como a sigla que dá nome a uma comunidade que milita pela obtenção de direitos para a educação pública, 


\section{Revista Docência e Cibercultura}

que considera esse tipo de recurso como um suporte da educação dos sujeitos, sem desprezar as suas experiências naturais e a realidade dos espaços em que estão inseridos.

A inserção de uma política de uso dos REA possibilita o intercâmbio de experiências entre os atores escolares (professor-estudante, estudante-estudante e estudante-recurso), evidenciando o princípio da Educação Aberta que é ter a interação como centro do processo educacional dos sujeitos, permitindo o sentir-se afetado pelas novas descobertas e responsável pela aprendizagem, pois cada sujeito no mundo precisa ser constantemente exposto ao seu próprio tempo.

Segundo Barbosa e Silva (2010, p. 20), a utilização de mídias digitais facilitadoras, inseridas na sociedade por meio da Interação Homem-Computador (IHC), possibilita a gestão dos conteúdos dentro deste contexto digital e esse mecanismo interacionista ajuda a formar os indivíduos para serem autores digitais mais responsáveis e permite que a partilha do conhecimento possa ser feita sem ferir os direitos autorais e ainda preste acessibilidade para que todos os públicos da sociedade utilizem os recursos de forma adaptável.

Atrelada a essa prática interacionista, existente entre os sujeitos e os recursos digitais tecnológicos, Alarcão (2011, p. 16-17) descreve a distância entre a evolução do compartilhamento de informações na internet e aquilo que é instruído nas escolas, argumentando que as instituições de ensino não detêm o monopólio do saber e que apesar de se constituir como uma organização, não possui um sistema aberto, pensante e nem flexível. É necessário que as escolas insiram em seus documentos norteadores as expertises da era digital, pois os sujeitos escolares já estão inseridos nessa realidade, mas acima de tudo que a escola se constitua como um espaço livre de si mesma e que seja aberta á comunidade em que está inserida.

As discussões sobre políticas públicas para REA são quase inexistentes, por isso, REA não é apenas um método inovador que visa o melhoramento da educação na sua atualidade, mas também como uma comunidade de sujeitos que milita por espaços, nos quais cada vez mais a Educação Aberta possa ter vez e voz e consigamos avançar no propósito de fazer com que a educação evolua democraticamente, na expansão territorial e nos tempos necessários por cada pessoa, a exemplo dos programas estabelecidos na educação básica e no ensino superior como o Programa Um Computador por Aluno (UCA) e a Universidade Aberta do Brasil (UAB).

Em 2010 foi encaminhada uma proposta de inserção da utilização dos REA no Plano Nacional de Educação (PNE), prevendo o investimento de mais 1,1 bilhão de reais que seriam gastos 


\section{Revista Docência e Cibercultura}

na aquisição, impressão e envio de cerca de 75,5 milhões de exemplares de livros didáticos para o triênio 2014-2016, segundo o Ministério da Educação (MEC), valores esses que poderiam ser reduzidos se tivéssemos a consciência de que uma grande parte dos nossos professores não utiliza o livro didático como sua única ferramenta de trabalho. Mas, de acordo com Rossini e Gonzalez (2015) em entrevista ao portal EBC (DUARTE; SANTANA, 2015) nem todas as solicitações foram atendidas:

os REA se encaixam em duas das metas do plano: a 5, que objetiva alfabetizar todas as crianças, no máximo, até o final do $3^{\circ}$ (terceiro) ano do ensino fundamental, e 7 , que trata do fomento à qualidade da em todas as etapas e modalidades, com melhoria do fluxo escolar e da aprendizagem de modo a atingir as seguintes médias nacionais para o Ideb. "Elas prevêm a diversidade de métodos e propostas pedagógicas, que devem ser disponibilizadas, preferencialmente, como recursos educacionais abertos e softwares livres" (grifo nosso), explica.

Tramita no Congresso Nacional o Projeto de Lei $n^{\circ}$ 1513/2011, apresentado pelo Deputado Paulo Teixeira (PT/SP), cuja emenda é dispor sobre a "política de contratação e licenciamento de obras intelectuais subvencionadas pelos entes do Poder Público e pelos entes de Direito Privado sob controle acionário de entes da Administração Pública”. Esse projeto visa definir e estabelecer parâmetros legais para a compra e disponibilização de material didático, inclusive exigindo do governo que materiais financiados com dinheiro público sejam livremente disponibilizados mediante autorização de seus autores.

Por outro lado, vemos o governo retroceder no seu projeto de promoção de uma Pátria Educadora, levando em consideração os cortes financeiros acometidos no quadriênio de 2015-2018, sobretudo no setor da Educação e pela aprovação de uma Base Nacional Comum Curricular (BNCC) que em nenhuma de suas 396 páginas cita a utilização de REA na Educação Básica.

O principal ganho da comunidade REA no Brasil foi à participação coletiva desta nas discussões, alterações e elaboração do PNE, que apresenta dez diretrizes e vinte metas para a Educação Básica. Das treze sugestões aprovadas na Câmara dos Deputados, apenas três foram aceitas quando o processo seguiu para o Senado Federal, conseguinte aprovação do PL nº 8035/2010, indexado na Lei Ordinária $\mathrm{n}^{\circ}$ 13005/2014 (BRASIL, 2014), fixadas nas metas cinco e sete, dadas a seguinte forma:

Meta 5: Alfabetizar todas as crianças, no máximo, até o final do terceiro ano do ensino fundamental. 


\section{Revista Docência e Cibercultura}

5.3) Selecionar, certificar e divulgar tecnologias educacionais para alfabetização de crianças, assegurada a diversidade de métodos e propostas pedagógicas, bem como o acompanhamento dos resultados nos sistemas de ensino em que forem aplicadas, devendo ser disponibilizadas, preferencialmente, como recursos educacionais abertos.

Meta 7: Fomentar a qualidade da educação básica em todas etapas e modalidades, com melhoria do fluxo escolar e da aprendizagem de modo a atingir as seguintes médias nacionais para o IDEB:

7.11) Selecionar, certificar e divulgar tecnologias educacionais para a educação infantil, o ensino fundamental e o ensino médio, assegurada a diversidade de métodos e propostas pedagógicas, com preferência para softwares livres e recursos educacionais abertos, bem como o acompanhamento dos resultados nos sistemas de ensino em que forem aplicadas.

7.13) Implementar o desenvolvimento de tecnologias educacionais, e de inovação das práticas pedagógicas nos sistemas de ensino, inclusive a utilização de recursos educacionais abertos, que assegurem a melhoria do fluxo escolar e a aprendizagem dos (as) alunos (as).

A partir da integração dos REA na educação por meio das metas cinco e sete do referido documento, fica evidente a sua ligação com as TDIC, porque estas formam uma teia de conhecimento muito vasta, na qual todo recurso disponibilizado e aplicado na educação pode ser licenciado, servindo para o melhoramento do sistema de ensino e do nível de aprendizagem, permitindo a criação de novas possibilidades de ensino e pesquisa na educação como um todo.

Segundo Amiel (2012, p. 17), a utilização de REA para educação não retira as características da escola, apenas busca aprimorá-las, pois a educação é um direito previsto em lei para todos, que garante permanência e acesso gratuito, apesar de muitas vezes prestar um serviço no qual cada sujeito é responsável pelo seu sustento intelectual. O PNLD é um exemplo de que nem sempre a aplicação de um recurso é o suficiente para divertir o âmbito da aprendizagem, pois é preciso permitir uma construção participativa sobre os aspectos e paradigmas da sociedade em determinada realidade, por exemplo: uma aula sobre a cultura dos povos indígenas, rica em recursos midiáticos e abordagens de assuntos diversos sobre os costumes dos índios é diferente de uma aula em que se utiliza apenas o que conta o livro didático.

Parte da conceituação teórica desses resultados apresentados já é utilizada no nosso dia a dia, mas falar em REA nos remete à ideia de que estamos trabalhando com o novo e muitas vezes aquilo que é novidade pode assustar, por isso apresentamos considerações de produção e utilização dos 


\section{Revista Docência e Cibercultura}

REA, propondo a construção de um Guia de Recomendações para a concepção de REA, no qual possamos abordar os objetivos específicos dos REA, a fundamentação legal (lei, decreto, declaração, manifesto e etc.), os princípios do REA (6R, Creative Commons e compartilhamento livre), as diretrizes educacionais (REA como políticas Públicas para Educação) e os procedimentos para produção do material.

\section{PRODUÇÃO E UTILIZAÇÃO DOS REA}

Este artigo é resultante de uma pesquisa acerca do uso e produção de REA para a educação. Embora a pesquisa se concretize como um estudo teórico sobre REA e suas especificidades, o caminho percorrido até alcançar um resultado satisfatório teve como objetivo apresentar condições físicas para que o uso de recursos digitais educacionais fossem tidos como facilitadores do processo de ensino e aprendizagem, não substituindo, mas aprimorando as teorias de aprendizagem já existentes no setor da educação e nos processos de escolarização dos sujeitos inseridos na realidade virtual.

Nesse sentido fizemos a análise da Lei de Preservação dos Direitos Autorais - Lei n ${ }^{\circ}$ 9.610/98 (BRASIL, 1998) - para detalhar as permissões legais do licenciamento de obras abertas e por fim investigar se o material disponível na internet pode ser utilizado como REA e se é correto afirmar que todo recurso que constitui um dado conhecimento, uma vez disponibilizado na internet, servirá para fins pedagógicos de forma aberta e gratuita. Além disso, pesquisamos a aplicabilidade da Teoria Conectivista, proposta por Siemens (2005) e Downes (2008), na produção dos REA, como por exemplo a elaboração de material didático para Curso Online Aberto e Massivo ou Massive Open Online Course (Moocs) - que são classes online sem limite de vagas -, que podem ocorrer por meio da partilha do conhecimento aplicado em formações suplementares (técnicas de fotografia, administração de pequenos negócios, conhecimentos básicos em informática, estudos temáticos em filosofia e sociologia entre outros) e a relação assíncrona que os sujeitos possuem com as ferramentas tecnológicas aplicadas na formalidade da Educação Aberta.

Nessa perspectiva, de acordo Liyoshi e Kumar (2008), que trazem em seu bojo uma coletânea de trabalhos que reafirmam a importância da educação aberta para todos os níveis e modalidades de ensino, principalmente no desenvolvimento cognitivo por meio das tecnologias colaborativas, 


\section{Revista Docência e Cibercultura}

fazendo uma reflexão acerca do protagonismo da Educação Aberta e da Teoria Conectivista, que faz analogia as sementes postas para o florescimento dos REA como tema central deste projeto e tantas outras colaborações.

Para compreendermos do que se tratam os REA, faz-se necessário primordialmente entender o conceito de Educação Aberta. Segundo Santos (2012, p. 71), a Educação Aberta se popularizou em 1970, como um movimento caracterizado pela possibilidade do compartilhamento livre. Não se sabe ao certo quando o termo começou a ser utilizado, mas a partir do momento em que a educação deixa de acompanhar as inovações do mundo tecnológico, uma das hipóteses que podemos abordar é a utilização dos recursos multimidiáticos para a formação dos sujeitos e não apenas como ferramenta de trabalho que o substituísse.

Segundo Santos (2012, p. 72) as definições acerca da Educação Aberta podem ser sistematizadas mediante as práticas de aprendizagem e a sua aplicabilidade, porque há um conjunto de dispositivos que tende a caracterizá-la como um método de ensino para o século atual, que une o modelo de aprendizagem ao momento histórico da era digital. Nesse sentido, a Educação Aberta configura-se na aprendizagem do sujeito no seu tempo/espaço/recurso, mas também na sua qualidade de vida, permitindo-lhe um ensino democrático, de produção e condução do conhecimento por meio de técnicas como:

- construção de uma plataforma híbrida, que permite o acesso livre;

- liberdade do estudante decidir onde estudar e que recurso utilizar;

- elaboração de tutoriais livres para prestar suporte pedagógico;

- utilização da autoaprendizagem para o reconhecimento formal ou informal da aprendizagem;

- isenção de taxas de matrícula e vestibulares, mensalidades e outros custos que seriam considerados uma barreira ao acesso à educação formal;

- certificação gratuita pelas participações em formação e contribuições online;

- acessibilidade nos cursos para estudantes com algum tipo de deficiência física, assim como os que estão em processo de vulnerabilidade social;

- produção coletiva de REA, utilizados tanto na educação formal quanto na informal. 


\section{Revista Docência e Cibercultura}

Tais peculiaridades promovem o acesso à educação por meio das TDIC, constituindo as práticas pedagógicas num modelo aberto e colaborativo, no qual os sujeitos partilham conhecimentos por meio da troca de experiências, impedindo a inferioridade no acesso à educação, principalmente no ensino superior, pois as novas didáticas surgem no espaço de formação docente e posteriormente refletem na educação (SANTOS, 2012, p. 72-73).

O método de trabalho da Educação Aberta é um contributo importante para que se pense práticas pedagógicas deterministas de uma geração conectada, é nesse sentido que Siemens (2005) e Downes (2008) propõem a Teoria Conectivista, que enfoca sobre as novas práticas de ensino e a maneira como o conhecimento se constitui no mundo dos conectados, mais precisamente nos espaços de aprendizagem e interação virtual.

Para Inuzuka e Duarte (2012, p. 196), o Conectivismo é a teoria de aprendizagem que leva em consideração a influência que as novas tecnologias atribuem à forma de comunicação e aprendizado dos indivíduos. Nesse sentido, Siemens (2005, p. 3) a define com base na análise das limitações de outras Teorias da Aprendizagem, tais como: Behaviorismo, Cognitivismo e Construtivismo, defendendo-a como uma nova perspectiva para a educação, que leva em consideração o processo de aprendizagem que ocorre fora dos indivíduos, incluindo o conhecimento que existe no interior das organizações e meios tecnológicos, a exemplo da cultura organizacional entre os indivíduos e os bancos de dados.

Kop e Hill (2008) argumentam que o Conectivismo também pode ser considerado um termo que faz alusão ao "conhecimento distribuído", o que justifica a ineficácia das teorias tradicionais de aprendizagem que se configuram apenas nas relações síncronas, quando é necessária a participação do estudante e do professor no mesmo instante e no mesmo ambiente, seja virtual ou presencial (webconferência, chats, fóruns etc.).

Sustentada pela epistemologia proposta por Downes (2018) e reforçada por Siemens (2008, p. 9) com base na Taxonomia de Aprendizagem de Mark Driscoll, que classifica a realidade da aprendizagem em quatro categorias elementares:

- objetivismo: afirma a realidade eterna e objetiva que ocorre fora dos indivíduos por meio do intercâmbio de experiências; 


\section{Revista Docência e Cibercultura}

- pragmatismo: afirma a realidade provisória pois o pertencimento intelectual é negociado entre o pensamento e as relações de experiências;

- interpretatismo: afirma a realidade interna por meio da construção do conhecimento;

- conhecimento acionável: composição das conexões e entidades conectadas.

Siemens (2008) e Downes (2018) afirmam que essa técnica suplementar que nos ajuda a entender, aprender e compreender de que forma o conhecimento se constitui nas especificidades da Teoria Conectivista (que é real), considerando que o nível de aprendizagem dentro dos ambientes virtuais não é inferior, pois é medido pela capacidade cognitiva dos sujeitos e não pelo tipo de recurso digital que é utilizado.

Segundo Mattar (2013, p. 24) a aprendizagem não é mais concebida apenas nas mentes dos indivíduos, mas também em contextos, relacionamentos e interações. Portanto, a Teoria Conectivista trata de práticas pedagógicas colaborativas, que leva em consideração o processo de aprendizagem democrático, autônomo e crítico que ocorre na interação dos atores escolas e na construção síncrona e assíncrona do conhecimento, face às novas realidades do desenvolvimento tecnológico e da sociedade organizada em rede, esclarecendo, nesse contexto, que o termo "aberta" que é facultado à educação e frequentemente associado a uma maior acessibilidade aos recursos.

Esse conceito de abertura e de práticas educacionais abertas (PEA) surge da transformação democrática das linhas de comunicação e informação da web 2.0, que se inserem no contexto da educação por meio das TDIC e possibilita a construção de outros modelos de aprendizagem que utilizam ferramentas multimidiáticas para facilitar a compreensão do conhecimento e se possível, fomentar outros espaços para (co)produção e (co)aprendizagem, a exemplo dos MOOCS (LITTO e MATTAR. 2017), que são cursos online gratuitos disponíveis para qualquer pessoa se inscrever.

Outros entendimentos podem surgir, como por exemplo o uso do termo "abertura", para ressignificar os espaços tradicionais da aprendizagem, pois uma das características da Educação Aberta é permitir que estudantes compartilhem e recebam conhecimentos por meio dos recursos digitais que lhes mantém conectados (computadores, notbooks, smartphones ou tablets) e que possibilita a prática do ensino democrático por conceder autonomia para que o educando administre o seu tempo de estudos conciliando-o a outras atividades que acometem a sua sobrevivência. 
De acordo com Spyer (2011, p. 21), o ensino online e as diversas formas de comunicação virtual, que incluem a sobrevivência humana, são fruto da evolução da internet entre os séculos $20 \mathrm{e}$ 21, se constituindo a cada dia como uma mídia diferenciada e universal, possibilitando que o contato virtual ocorra de forma simultânea entre os sujeitos, permitindo ainda que a partilha de informações entre duas vias que se comunicam, possa ser também compartilhada e reutilizada por outras vias.

Se juntarmos, por exemplo, a comunicação que ocorre num telefonema entre duas pessoas (1) e uma aglomeração de amigos que se reúnem para assistir a um jogo de Copa do Mundo pela televisão (2), veremos que a internet é um conjunto de colaborações que mistura a difusão transmitida por uma única informação dada para várias pessoas com a interatividade que é característica da comunicação de duas vias (3), fomentando um espaço virtual para o intercâmbio de experiências, que denominamos de social software. 


\section{Revista Docência e Cibercultura}

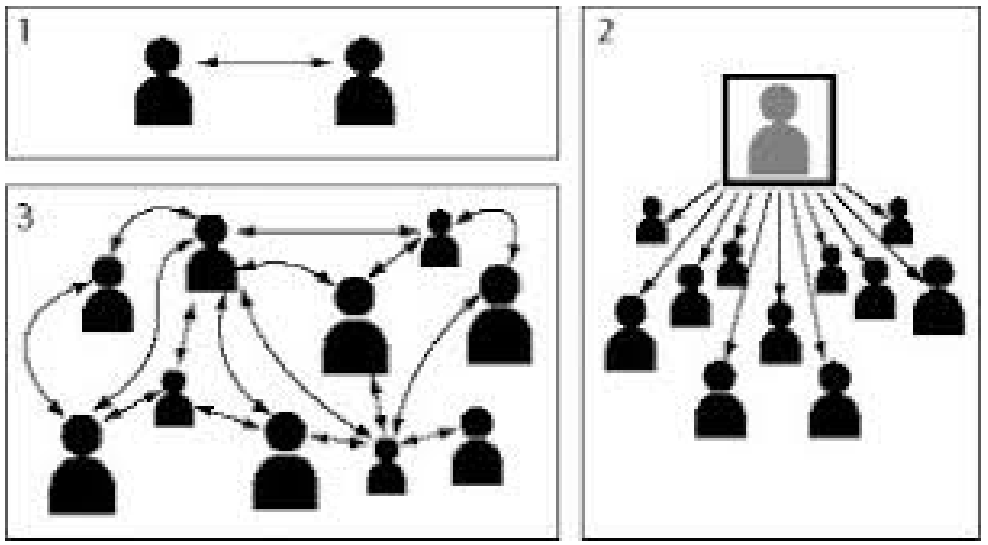

Figura 1 - Exemplos de comunicação

É nessa junção de comunicação e interação que o movimento open e a cultura livre estão presentes, integralizados pelas ações pedagógicas da educação aberta e a proposta da Teoria Conectivista, que visa disseminar o compartilhamento de novas ideias para gerar mais ideias, tendo as redes sociais digitais como fontes potencializadoras desse processo, neste caso, dentro e fora da escola (SEBRIAM et al. 2017, p. 18).

Outrossim, é importante refletir sobre o uso responsável dos recursos disponíveis na internet e que dão uma sensação de liberdade, pois não é comum a prática de analisar se determinado recurso está licenciado ou autorizado para o compartilhamento, porque podem existir produções que mesmo fazendo referência ao autor não é permitido fazer uso delas. Por exemplo, é natural utilizarmos o Google Imagem para indexar ilustrações aos nossos textos ou simplesmente postar fotografias com mensagens motivacionais nas redes sociais, fazendo referência ao autor e local de origem daquela figura, mas essa prática pode não ser correta, porque se analisarmos profundamente a Lei de Preservação dos Direitos Autorais no Brasil - Lei no 9.610/98 (BRASIL, 1998), constataremos que ela protege obras físicas, já as de cunho virtual, que denominaremos aqui de "dados conectados", recebem um código que geralmente identifica o criador e se determinada imagem pode ser utilizada de forma aberta, ou seja, os recursos online de qualquer espécie só podem ser utilizados para outros fins se o autor de determinado recurso autorizar o uso da obra.

Quem cria é proprietário do direito autoral e não importa o local de disposição do material, mas o universo da internet possui uma grande camada de materiais que estão sendo utilizados por 


\section{Revista Docência e Cibercultura}

terceiros que talvez não façam ideia de que estão cometendo crimes que ferem a legislação, caso a lei seja aplicada frente às interfaces mais populares da internet, os crimes acometeriam os níveis de propriedade intelectual, direito de uso, direito de distribuição e exploração comercial.

Pensando na disposição de novas práticas de ensino e espaços virtuais de compartilhamento de materiais que se configurem como um recurso aberto, mas sobretudo para indicar diretrizes para o uso responsável dos instrumentos licenciados, propomos algumas indicações para a elaboração de um guia de recomendações para a utilização de REA, que leve em consideração a sua metodologia ativa para a educação, pois no exterior das instituições de ensino há uma série de dados que se conectam por meio da interação e esse tipo de conteúdo compartilhável muitas vezes é desprezado e nem sempre reutilizado para fins educacionais, desvirtuando a ludicidade e o dinamismo que são muito mais interessantes do que as propostas de ensino tradicionais (SILVA et al. 2017, p. 2).

\section{ELEMENTOS PARA CONSTRUÇÃO DO GUIA DE RECOMENDAÇÕES PARA A UTILIZAÇÃO DE REA}

Seixas e Mendes (2006) argumentam que ao se utilizar o termo "guia", sobretudo na perspectiva de um sistema, este deve transcorrer sobre o caminho a ser percorrido, evidenciando projetos e explicitando as práticas do seu uso no tipo, na busca e na normatização.

Nesse sentido é importante que o guia proposto atenda a realidade da instituição em que se aplicar e os perfis de seus respectivos agentes, além de ser amplamente divulgado e disponibilizado de forma aberta e gratuita. Trataremos da composição do guia a partir de indicações para a produção e uso dos REA, que se assemelha na forma de um protótipo de letramento digital, pois entendemos que um guia de recomendações parte de uma construção coletiva e de discussões periódicas acerca de seus conteúdos essenciais.

\section{Conteúdo do guia}

O Guia de Recomendações pode ser esquematizado mediante os três elementos principais em que estão baseados os REA, proposto por Carolina Rossini, em entrevista para o portal EBC no ano de 2015 (DUARTE; SANTANA, 2015), e outros pesquisadores na origem do projeto Rea.net.br. 


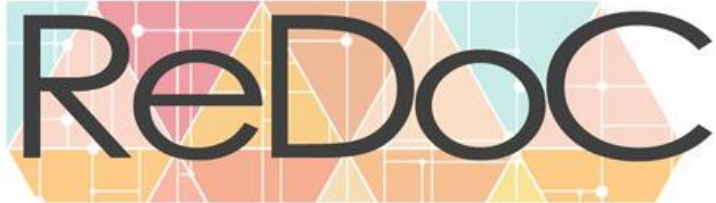

\section{Revista Docência e Cibercultura}

Nesse sentido, sugerimos que em um guia inclua-se as mesmas especificidades do REA no tipo, na busca e na normatização e que este se torne um documento livre para que qualquer sujeito consiga compreendê-lo e reutilizá-lo mediante a sua necessidade:

I. Conteúdos de aprendizado, todo material disponível livremente em rede, como livros, imagens ou até mesmo cursos que sejam utilizados para fins educacionais, por exemplo, os MOOC;

II. Ferramentas tecnológicas, que possibilitam gerenciar ou disponibilizar esse conteúdo online, fazendo uso da política dos 6R (revisar, reutilizar, remixar, redistribuir, reter e reiniciar);

III. Recursos para implementação, que são as licenças de propriedade intelectual para promover a publicação aberta de materiais que estejam licenciadas em $C C$ e o conhecimento prévio das limitações legais abarcadas pela Lei $n^{\circ}$ 9.610/98 que dispõe para reuso apenas as obras que estejam em domínio público.

Para complementar a elaboração do guia, também propomos incluir no documento, as limitações da Lei $\mathrm{n}^{\circ}$ 9.610/98, porque entendemos que os REA não fazem crítica à forma como se dá a legislação, mas é um complemento jurídico segundo o qual é permitido e autorizado fazer uso daquilo que está disponível em REA, portanto este documento também trará um importante alerta aos tipos de crimes que a lei aborda, tais como: pirataria, fotocópia, plágio etc, e as especificidades das licenças em $C C$, que detalham os perfis de licenciamento dos autores e deixe evidente que este mecanismo é o mais seguro e utilizado na comunidade REA, justamente por reunir liberdades e restrições, tais como: domínio público, atribuições livres, obras não derivativas, uso não comercial e compartilhamento pela mesma licença, conforme demonstra a Tabela 1:

Tabela 1. Combinação de perfis de autoria e os tipos de licenciamento

\begin{tabular}{|c|c|}
\hline Logotipo & Atribuições \\
\hline & Obras em Domínio Público (ODP) \\
\hline \multirow[t]{3}{*}{ () PUBLIC } & Permite que as obras que não são mais restritas por direitos autorais sejam marcadas \\
\hline & $\begin{array}{l}\text { como ODP de uma maneira padrão e simples, tornando-as facilmente detectáveis e } \\
\text { disponíveis para outras pessoas. }\end{array}$ \\
\hline & Atribuição (by) \\
\hline
\end{tabular}




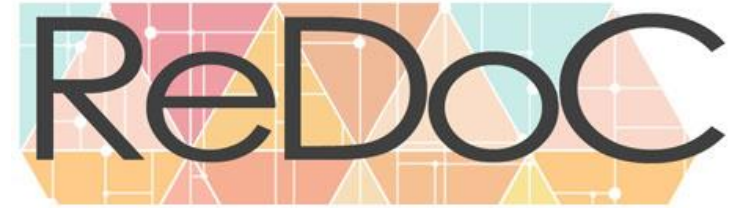

Revista Docência e Cibercultura

\begin{tabular}{|c|c|}
\hline & $\begin{array}{l}\text { a licença mais permissiva do leque de opções. A utilização da obra é livre, } \\
\text { dendo os utilizadores fazer dela uso comercial ou criar obras derivadas a partir da } \\
\text { ora original. Essencial é, apenas, que seja dado o devido crédito ao seu autor. }\end{array}$ \\
\hline & $\begin{array}{l}\text { tribuição - Uso Não-Comercial (by-nc) } \\
\text { autor permite uma utilização ampla da sua obra, limitada, contudo, pela } \\
\text { mpossibilidade de se obter através dessa utilização uma vantagem comercial. É } \\
\text { ambém essencial que seja dado o devido crédito ao autor da obra original. }\end{array}$ \\
\hline (i) & $\begin{array}{l}\text { Atribuição - Partilhe nos Termos da Mesma Licença (by-sa) } \\
\text { Quando um autor opte pela concessão de tal licença pretenderá, não só que lhe seja } \\
\text { dado crédito pela criação da sua obra, como também que as obras derivadas desta } \\
\text { sejam licenciadas nos mesmos termos em que o foi a sua própria obra. Esta licença } \\
\text { é muitas vezes comparada com as licenças de software livre. }\end{array}$ \\
\hline$\Theta_{10}$ & $\begin{array}{l}\text { Atribuição - Proibição de realização de obras derivadas (by-nd) } \\
\text { Permite a redistribuição, comercial ou não-comercial, desde que a sua obra seja } \\
\text { utilizada sem alterações e na integra. É também essencial que seja dado o devido } \\
\text { crédito ao autor da obra original. }\end{array}$ \\
\hline & $\begin{array}{l}\text { Atribuição - Uso Não-Comercial - Partilha nos Termos da Mesma Licença } \\
\text { (by-nc-sa) } \\
\text { Permite a redistribuição, comercial ou não-comercial, desde que a sua obra seja } \\
\text { utilizada sem alterações e na integra. É também essencial que seja dado o devido } \\
\text { crédito ao autor da obra original. }\end{array}$ \\
\hline (c) & $\begin{array}{l}\text { Atribuição - Uso Não-Comercial - Proibição de Realização de Obras } \\
\text { Derivadas (by-nc-nd) } \\
\text { Esta é a licença menos permissiva do leque de opções que se oferece ao autor, } \\
\text { permitindo apenas a redistribuição. Mediante adoção desta licença, não só não é } \\
\text { permitida a realização de um uso comercial, como é inviabilizada a realização de } \\
\text { obras derivadas. Dada a sua natureza, esta licença é muitas vezes chamada de } \\
\text { licença de "publicidade livre". }\end{array}$ \\
\hline
\end{tabular}

Fonte:

https://

br.creat

ivecom

$\underline{\text { mons.o }}$

$\underline{\text { rg/licen }}$

cas/

utros

fatore

$\mathrm{s}$

releva

ntes

també

$\mathrm{m}$

pode

$\mathrm{m}$

incre

menta

$\mathrm{r} \quad \mathrm{o}$

conte

údo

de um

guia,

como as diretrizes para o consumo responsável dos conteúdos disponibilizados na internet, uma vez que não se pode utilizar REA somente para gerar algum tipo de lucratividade, pois o acesso ao conhecimento, informação e cultura são valores éticos, e a manutenção dos dados disponibilizados 


\section{Revista Docência e Cibercultura}

em rede, o que é mais difícil de estabelecer nas instituições, pois ainda estamos adaptados a engavetar projetos que caem no desuso, por desconhecer que este trabalho pode ser revisto, modificado e até aplicado em outra instituição, a exemplo de uma produção mais simples, como um plano de aula, que pode ser revisado, reutilizado, remixado e/ou compartilhado entre os professores de uma escola.

\section{Forma de acesso}

As contribuições não estão apenas nos conteúdos que devem constar no guia, mas na estratégia de manter estas atribuições visíveis e disponibilizadas abertamente para o público de pesquisadores, portanto também propomos a criação e implementação de uma aplicação digital híbrida para disponibilizar o Guia de Recomendações, denominada no letramento digital como a sexta liberdade (6R) ou pelo codinome "Restart", que não se restrinja apenas a um tipo de sistema operacional (SO) e dispositivo digital (computador, smartphone e tablet), mas que contemple usuários iOS; Android, BlackBerry, Windows Phone, Linux e suas distribuições, Windows e macOS e todos os dispositivos digitais, pois é necessário o acesso uniforme à todos os tipos de usuários, adequando-se à realidade de cada professor e estudante da rede de ensino básico.

A partir desse entendimento Restart constitui-se como um ambiente aberto, totalmente gratuito e que possui informações acerca da utilização e criação dos REA, é uma plataforma que visa disponibilizar informações precisas para todos os tipos de dispositivos digitais, como smartphones, tablets, laptops (computadores de colo) e desktops (computadores de mesa), pois não se limita a um único tipo de usuário e nem a um único tipo de SO.

Segundo Chammas et al (2014), os mais expressivos em termos de mercado de aplicativos (apps) são: iOS, Android, Blackberry e Windows Phone. Nesse sentido pensamos em como o guia será distribuído, dentre as principais formas de apps existentes no artigo dos autores citados, o webapp híbrido é o único que se adequa às exigências da nossa proposta, pois a sua funcionalidade abrange qualquer modelo de dispositivo digital, sob o uso exclusivo de um navegador (browser), face a tipologia e a variação de SO. O web-app híbrido se adequa à todas as resoluções de tela e às mais variadas arquiteturas de sistema, facilitando sua distribuição em massa, pela facilidade de ser executado em qualquer gadget (dispositivo) que contenha acesso à internet. 


\section{Revista Docência e Cibercultura}

A Restart irá se apresentar como uma ferramenta informativa, consultiva e de contribuição sobre REA, seguindo os requisitos apresentados neste protótipo. A mesma deve conter todas as informações baseadas nas contribuições abertas, permitindo que o usuário desfrute da política das quatro liberdades (revisar, reutilizar, remixar e redistribuir), além da proposta de Wiley (2014) da quinta liberdade (5R) "retain" (tradução: reter), que propõe a posse de conteúdo da comunidade aberta, pois defende a necessidade de facilitar o entendimento dessas liberdades na aquisição de novos recursos, como também na sua aplicabilidade para se tornar um recurso aberto e gratuito (LITTO; MATTAR, 2017, p. 32).

Portanto, a sexta liberdade é a plataforma Restart configurada no modelo web-app híbrido, que visa uma melhor organização e contabilização dos conteúdos em REA e a reinicialização no tratamento de ODP, através da disponibilização de infográficos estatísticos e informações separadas por temas e assuntos. Com isso, o usuário estará acessando um ambiente digital totalmente formatado e construído nos princípios e políticas dos REA, dispondo de informações livres para a utilização da proposta de Educação Aberta. Mas para produzir uma plataforma não basta apenas a vontade de construí-la, antes é necessário planejar a sua interface e qual o tipo de usuário padrão, analisar os dispositivos que irão suportar uma plataforma digital, verificar os sistemas e arquiteturas operacionais. Além de otimizar os tipos de dados que serão disponibilizados, a interação do sistema com o usuário e todo o tratamento de banco de dados para a implementação da disponibilização do Guia de Recomendações.

Segundo Ribeiro et al (2006, p. 1-6), o desenvolvimento de um sistema web requer conhecimentos avançados em linguagens de programação, como Python e $P H P$, ou linguagens de marcação, como Cascading Style Sheets (CSS), Hypertext Markup Language (HTML), JavaScript, entre outras. Além disso postula um alto nível de conhecimento em banco de dados, pois a plataforma necessita da integração e fluxo de dados entre as obras licenciadas em domínio público e $C C$, além da necessidade de portar dados de repositórios em REA, que inicialmente parece difícil para os pesquisadores da área de Educação, mas que na visão dos pesquisadores desse projeto é uma rica oportunidade de transdisciplinaridade junto à área da Ciência da Computação.

\section{Método de trabalho}


Não existe uma metodologia para tratar das especificidades da construção de um ou mais REA, porém um dos métodos que podem facilitar passo a passo a criação e condução dos recursos abertos e que pode ser adotado dentro de um guia de recomendações é a Ergonomia em relação ao conceito de Educação Aberta, pois esta busca compreender como as interações humanas ocorrem nos diversos elementos ou sistemas, visando aperfeiçoar o bem-estar humano nas relações, diante dos domínios físicos, cognitivos e organizacionais.

Para a Associação Brasileira de Ergonomia (ABERGO), a definição da ergonomia física está ligada à forma como as atividades do trabalho humano são desenvolvidas, relatando um estudo sobre as posturas, o manuseio e os movimentos, averiguando os melhores aspectos para assegurar saúde e segurança. A ergonomia cognitiva está diretamente adstrita aos processos mentais, compreendendo o raciocínio, a memória, as percepções humanas e como estes processos influenciam as funções motoras e afetam as relações interpessoais entre os seres humanos e os elementos de um sistema, estudando como ocorre o processo de tomada de decisões, a interação entre homem e computador, o stress e a carga mental necessária para o desenvolvimento do trabalho. Já a Ergonomia Organizacional diz respeito ao aprimoramento dos sistemas sóciotécnicos, abrangendo a comunicação, o gerenciamento de recursos, a organização do tempo para o trabalho, o trabalho em grupo e cooperativo, a cultura organizacional e a gestão de qualidade.

Segundo Rebelo (2017, p. 16) o objeto de estudo da Ergonomia é a observação das interações Humanas com o universo existencial. "E é precisamente com estas interações que a Ergonomia se preocupa, quer se manifestem numa situação de trabalho, quer durante a utilização de um eletrodoméstico em nossa casa". O objetivo da Ergonomia é promover um upgrade entre essas interações, para assim proporcionar o bem-estar, saúde e segurança do indivíduo.

No campo educacional a Ergonomia pode ser utilizada como um método de trabalho para o desenvolvimento de recursos abertos, incluindo a preparação do próprio Guia de Recomendações, pois facilita a construção colaborativa e o intercâmbio de experiências via partilha de dados, promovendo estratégias de aprendizagem para auxiliar na inserção e distribuição de dados conectados.

Outro fator importante que podemos abordar com a fusão dos conceitos de Ergonomia e Educação Aberta, são as estratégias de utilização de mídias sociais que podem servir de mecanismos de interação que promove a aprendizagem por meio do compartilhamento de recursos abertos em 


\section{Revista Docência e Cibercultura}

benefício do desenvolvimento profissional de professores. E para sustentar essa ideia analisamos alguns aplicativos móveis (Tabela 2) e de que forma as suas funcionalidades podem ajudar educadores no processo de ensino e aprendizagem com REA.

Tabela 2. Análise dos apps móveis

\begin{tabular}{|c|c|c|}
\hline Aplicativo & Função & Principais aspectos \\
\hline Outlook & $\begin{array}{l}\text { Comunicar, armazenar e } \\
\text { elaborar }\end{array}$ & $\begin{array}{l}\text { Apesar de possuir a mesma finalidade de outros serviços, que é } \\
\text { enviar e receber e-mails, este dispositivo web disponibiliza para os } \\
\text { seus usuários um pacote office (word, excel, power point, one drive } \\
\text { e one note) completo e virtual, que pode facilitar as construções } \\
\text { coletivas dos recursos licenciados, bem como o seu armazenamento } \\
\text { e compartilhamento, sem precisar fazer download do arquivo antes } \\
\text { do envio. }\end{array}$ \\
\hline Gmail & $\begin{array}{l}\text { Comunicar, armazenar e } \\
\text { discutir }\end{array}$ & $\begin{array}{l}\text { Possue dispositivos secundários que podem facilitar o diagnóstico } \\
\text { dos materiais a serem disponibilizados abertamente e a coleta de } \\
\text { dados que pode ser feita a partir do uso do Google docs. Além disso } \\
\text { dispor de instrumento digital para webconferência (hangout) e chat } \\
\text { (talk-Gmail). }\end{array}$ \\
\hline Trello & Organizar & $\begin{array}{l}\text { Gerenciamento de projetos, criação de checklist, compartilhamento } \\
\text { das atividades entre grupos, controle do progresso dos itens já } \\
\text { executados. }\end{array}$ \\
\hline Facebook & Publicar & $\begin{array}{l}\text { Compartilhamento de trabalhos, uso de grupos para troca de ideias e } \\
\text { publicação de trabalhos. }\end{array}$ \\
\hline Twitter & $\begin{array}{l}\text { Compartilhar / } \\
\text { Quantificar }\end{array}$ & $\begin{array}{l}\text { Por ter quantidade de caracteres pode ser utilizado para } \\
\text { compartilhamento de conteúdo vinculado a um link de } \\
\text { redirecionamento para os trabalhos completos. } \\
\text { Uso de hashtag (\#) para identificar o tema do conteúdo afim de } \\
\text { identificar o público alcançado e mensurar o nível de interesse. }\end{array}$ \\
\hline WhatsApp & Articular & $\begin{array}{l}\text { Utilizado como meio para reuniões para troca de ideias e } \\
\text { informações através de grupos. }\end{array}$ \\
\hline Instagram & & O compartilhamento através de imagens, podendo haver a mesma \\
\hline
\end{tabular}




\section{Revista Docência e Cibercultura}

\begin{tabular}{|l|l|l|}
\hline Quantificar & $\begin{array}{l}\text { funcionalidade do Twitter através do uso das hashtag (\#) para } \\
\text { mensurar o nível de interesse. }\end{array}$ \\
\hline
\end{tabular}

Fonte: o autor

Segundo Litto e Mattar (2017, p. 41), os REA "podem fornecer inspiração e ideias ao desenvolver os próprios recursos ou expor diferentes práticas”. É nesse sentido que objetivamos a utilização de REA na educação por intermédio da metodologia de trabalho incorporada no conceito de Ergonomia, que potencializa o fazer pedagógico dos professores levando em consideração o seu bem-estar, saúde e segurança.

\section{Avaliação aberta}

Um dos instrumentos mais importantes dos processos educativos é a avaliação, porque independentemente do tipo podemos ter o feedback positivo ou negativo acerca do que estamos propondo, além de permitir o acompanhamento e as orientações necessárias para a aprendizagem. Com base na epistemologia da Teoria Conectivista e nas contribuições históricas da Educação Aberta propomos uma etapa avaliativa que valide o Guia de Recomendações conforme a realidade de seu público alvo (professores e estudantes), a exemplo do projeto político-pedagógico (PPP) das instituições de ensino que precisa ser construído de forma democrática, coletiva, participativa e avaliativa, ao mesmo tempo em que sofre as interferências de seus criadores e do tempo.

Conforme Erthal (2015, p. 11) a avaliação possibilita que os profissionais se questionem sobre o seu próprio processo educativo frente ao resultado daquilo que foi avaliado, podendo ser cumulativa, classificatória ou sistematizada. Mas no sentido de promover a abertura das possibilidades engendradas nos REA, fica a critério dos professores e estudantes o tipo de avaliação a ser aplicada na validação do guia, porque a intenção é coletar as contribuições externas de pesquisadores da área de Educação e Computação, visando o aperfeiçoamento desse guia e dos conteúdos nele dispostos.

Desde o início do trabalho esclarecemos a não apresentação de um Guia de Recomendações já concluído, pois não se pode constituir um material deste tipo e com todas essas especificidades sem antes argumentar a importância da usabilidade dos REA, é o mesmo que construir uma casa sem alicerce e torcer para que as paredes não caiam. Para evitar o desuso, caso o guia fosse concluído e 


\section{Revista Docência e Cibercultura}

amplamente divulgado, optamos por apresentar indicações elementares para a produção, uso e concepção do Guia de Recomendações, indicando conteúdos de licenciamento, forma de acesso, metodologia para criação e execução e uma avaliação aberta.

\section{AVALIAÇÃO DOS ELEMENTOS NORTEADORES PARA A CONTRUÇÃO DO GUIA DE RECOMENDAÇÃO}

Para validar os conteúdos elementares para a condução e elaboração de um guia, sobretudo em sua fase de letramento digital, foi solicitado, por meio de comunicação eletrônica, à profissionais das áreas da Psicologia, Educação e Computação que analisassem o material apresentado a partir dos conteúdos expostos na proposta de materialização do guia (em tela). O critério de escolha dos profissionais levou em consideração as áreas de atuação desses professores, sobretudo as linhas de estudos acerca do Desenvolvimento Humano, das TDIC e do Desenvolvimento Mobile.

Após foram encaminhadas as orientações para a execução do processo de validação, elencando alguns questionamentos norteadores para o exercício proposto, cujo resultado obtido consta na Tabela 3. As questões foram baseadas nos conteúdos do documento, visando à compreensão sobre o entendimento:

a) da importância da construção de um guia de recomendações para a utilização de REA;

b) da base teórica que deve ser apresentada no documento (acrescentando possíveis sugestões);

c) das especificidades da comunidade livre e dos princípios legais que norteiam a utilização dos REA;

d) da proposta da sexta liberdade, "restart", que visa à organização de uma plataforma híbrida para a disponibilização do guia e outros conteúdos;

e) do método de trabalho entremeio dos conceitos de Ergonomia e Educação;

f) do tipo de avaliação.

As contribuições dos docentes/pesquisadores das áreas da Psicologia, Educação e Computação foram tabuladas de acordo com a ordem de recebimento dos resultados encaminhados via $e$-mail, contendo em forma de texto as arguições dos seis profissionais de ensino superior acerca da proposição dos elementos norteadores de usabilidade de REA para a preparação de um guia de recomendações. A tabela 3 apresenta uma compactação das contribuições dos profissionais 


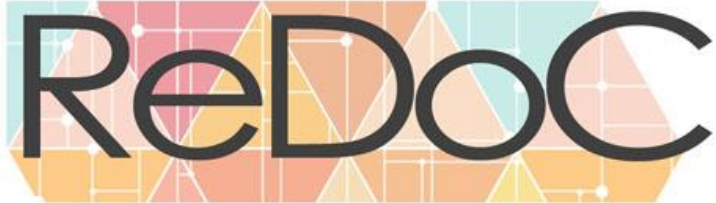

Revista Docência e Cibercultura

pesquisados, obedece a ordem da obtenção dos resultados, a lotação dos profissionais e a classificação dos resultados em significativo e não significativo, representada pelas imagens e

Tabela 2. Levantamento dos dados de validação do guia

\begin{tabular}{|c|c|c|c|}
\hline & Lotação & Considerações & Resultado \\
\hline Docente 1 & $\begin{array}{l}\text { Instituto de Psicologia } \\
\text { (IP)/UFAL }\end{array}$ & $\begin{array}{l}\text { Avaliou a proposta como inovadora e } \\
\text { considerável, apesar de ter dúvidas na } \\
\text { forma como se daria a inserção de um Guia } \\
\text { na universidade. Foi então que } \\
\text { relembramos parte do texto em que } \\
\text { relatamos a necessidade de introduzi-lo na } \\
\text { formação de professores, para que esta } \\
\text { prática se dissemine. }\end{array}$ & \\
\hline Docente 2 & $\begin{array}{l}\text { Centro de Educação } \\
(\mathrm{CEDU}) / \mathrm{UFAL}\end{array}$ & $\begin{array}{l}\text { Avaliou a proposta como inovadora e se } \\
\text { dispôs a discutir o assunto para além de } \\
\text { uma pesquisa de validação de um } \\
\text { documento, pois acredita que a } \\
\text { universidade necessita passar por processos } \\
\text { de inovação no ensino. }\end{array}$ & \\
\hline Docente 3 & $\begin{array}{l}\text { Instituto Federal de } \\
\text { Alagoas/Educação }\end{array}$ & $\begin{array}{l}\text { Evidenciou questões pertinentes à } \\
\text { materialização do documento no âmbito de } \\
\text { informação e também formação. } \\
\text { Considerou uma iniciativa excelente e } \\
\text { criticou a ideia negativa que as instituições } \\
\text { possuem sobre os conhecimentos da } \\
\text { internet, dados de forma aberta. Sugeriu } \\
\text { que a inserção do entendimento de REA } \\
\text { possa atingir uma instância maior, sendo } \\
\text { incorporado pela gestão pedagógica dos } \\
\text { cursos e assim integrar os documentos } \\
\text { norteadores das instituições. }\end{array}$ & \\
\hline
\end{tabular}




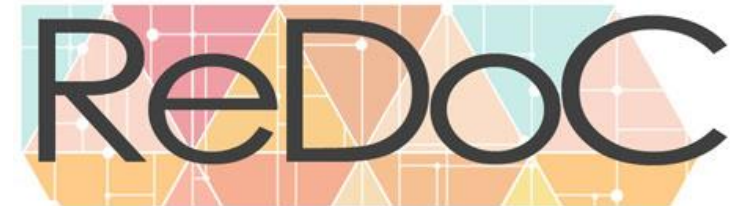

Revista Docência e Cibercultura

\begin{tabular}{|c|c|c|}
\hline Docente 4 & $\begin{array}{l}\text { Núcleo de Informática } \\
\text { Aplicada à Educação } \\
\text { (NIED)/UNICAMP } \\
\text { Integrante da Cátedra da } \\
\text { Unesco em Educação } \\
\text { Aberta }\end{array}$ & $\begin{array}{l}\text { Avaliou como sendo importante a proposta } \\
\text { do Guia e apesar de não ter participado do } \\
\text { processo de validação do protótipo, } \\
\text { anteriormente. Indicou leituras sobre } \\
\text { políticas públicas de REA, incentivando a } \\
\text { continuidade nos processos já existentes. } \\
\text { Optamos em inicialmente adaptar o } \\
\text { entendimento de REA à nossa realidade, } \\
\text { revisamos os conteúdos norteadores que se } \\
\text { somam às práticas de políticas públicas } \\
\text { propostas por pesquisadores da área. }\end{array}$ \\
\hline Docente 5 & $\begin{array}{lr}\text { Instituto de } & \text { Ciências } \\
\text { Biológicas e } & \text { Sociais } \\
\text { (ICBS)/UFAL } & \end{array}$ & $\begin{array}{l}\text { Solicitou uma reunião coletiva para melhor } \\
\text { discutimos a proposta do protótipo. }\end{array}$ \\
\hline Docente 6 & $\begin{array}{l}\text { Instituto de Computação } \\
\text { (IC)/UFAL }\end{array}$ & $\begin{array}{l}\text { Fez correções essenciais na escrita e } \\
\text { metodologia do documento que propomos, } \\
\text { realizou discussões plausíveis, } \\
\text { considerando pertinente o objetivo do Guia. }\end{array}$ \\
\hline
\end{tabular}

Fonte: Os autores

Para otimizar os resultados na Tabela 3, analisamos as contribuições dos docentes pesquisados, levando em consideração as respectivas áreas de atuação. Para a Docente 1 da Psicologia, queríamos saber das possíveis problemáticas da implantação de um Guia de Recomendações, desde que construído coletivamente, pois compete a sua área de estudos analisar a adaptação dos sujeitos ao novo e também a percepção das mudanças de espaço, uma vez que o método de trabalho proposto é a Ergonomia e nela prevalece o bem-estar, a saúde e a segurança dos trabalhadores/colaboradores, o resultado foi positivo e concordamos que a proposta deve ser inserida ainda na formação de professores, para que possa se disseminar para outros setores da educação.

Na visão dos Docentes 2, 3 e 4 da área das TDIC a proposta tem grande importância, nesse sentido introduzimos no texto as contribuições recebidas e que foram relevantes para a condução e materialização dos conteúdos do guia de recomendações, o resultado foi bastante significativo e 


\section{Revista Docência e Cibercultura}

conseguimos avançar sobre vários conceitos de REA, inclusive no tipo de avaliação aberta que estamos propondo. Já a Docente 5, apesar de achar a proposta pertinente, preferiu se reunir com o grupo para discutir sobre as especificidades da temática, mas a mesma não tinha disponibilidade para nos atender dentro prazo estabelecido para a devolutiva dos nossos resultados, sendo assim, computamos a sua não-contribuição como um fator negativo.

De acordo com o Docente 6, a proposta é bastante inovadora, mas precisava de ajustes com relação ao desenvolvimento tecnológico e o tipo de ferramenta que melhor comportasse o guia de recomendações, nesse caso, o mesmo nos indicou leituras com ênfase no desenvolvimento de webapps híbridos e se dispôs a nos auxiliar, foi então que firmamos a parceria entre Pedagogia e Ciência da Computação.

As contribuições dos pesquisadores, além de ocorrer de forma democrática e participativa, pode ser entendida também como um importante instrumento diagnóstico para detectar as necessidades técnicas das instituições públicas de ensino sob a ótica dos avanços tecnológicos, pois a diversidade dos métodos para a educação está nas propostas de utilização dos recursos potencializadores da aprendizagem, como os REA que permitem à qualquer pessoa, mediante vínculo de aprendiz, construir novas ideias por meio da (co)produção e da (co)aprendizagem sem precisar mercantilizar o seu acesso às produções científicas disponibilizadas em rede.

Propomos neste artigo diálogos pertinentes para o avanço da produção científica na área da Educação, mais precisamente no entendimento de que buscamos uma educação participativa, democrática, popular e altamente referenciada, que possa ir além dos muros paliativos das instituições de ensino, passando a incorporar as experiências existentes dessa extensão comunidadeescola e na interação entre os seus agentes.

\section{CONSIDERAÇÕES FINAIS}

O estudo aqui apresentado é analítico e investigativo, firmado na pesquisa com REA e não apenas sobre REA. Sua relevância está na proposta pedagógica que visa disseminar a produção do conhecimento por meio da Educação Aberta no processo de ensino e aprendizagem dos sujeitos, incorporando-se aos documentos norteadores de gestão pedagógica com objetivo de dar diretrizes e traçar metas de ensino e aprendizagem para gerar resultados significativos em todos os níveis e 


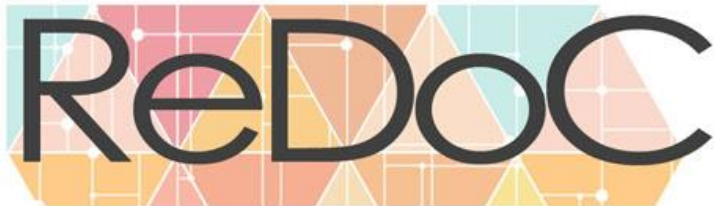

\section{Revista Docência e Cibercultura}

modalidades da educação, disponibilizando não só o entendimento de práticas de usabilidade, mas também a superfície democrática que promove a participação de pesquisadores de outras áreas do conhecimento, fomentando espaços de discussões acerca das políticas públicas para REA e a sua institucionalização.

Atualmente é muito comum em outros países a utilização de REA nas produções de $M O O C$ que são cursos online abertos, sem limitação de vagas, ofertados por meio de ambientes virtuais de aprendizagem (AVA), oferecendo a milhares de pessoas a oportunidade de ampliar seus conhecimentos num processo de (co)produção e (co)aprendizagem. No Brasil as discussões provocam setores da Administração Pública para que aprovem a utilização de REA nos documentos norteadores da Educação, propondo parâmetros legais para a compra e disponibilização de material didático.

A pesquisa é importante para construir espaços de discussão e formação acerca da utilização dos REA, promovendo diálogos sobre a implementação de novas políticas públicas educacionais e práticas pedagógicas que abordem as especificidades da Educação Aberta e da Teoria Conectivista para a elaboração do Guia. Outro fator importante é a utilidade da Ergonomia como método de trabalho para a produção e execução dos REA, além de propostas inovadoras que visem a acessibilidade desses recursos, mas é importante propiciar o conceito de abertura propondo que o Guia se faça democrático, participativo e que seja amplamente divulgado, visando atender à realidade da instituição em que se incorpora e que aborde conteúdos pertinentes à produção e organização dos REA.

\section{REFERÊNCIAS}

ABERGO. $O$ que é Ergonomia? Disponível em: $<\mathrm{http}: / / w w w . a b e r g o . o r g . b r / i n t e r n a s . p h p ? p g=$ __que_e_ergonomia> Acesso em: 10 jan.2018. ALARCÃO, I. Professores reflexivos em uma escola reflexiva. 8. ed. São Paulo: Cortez, 2011. AMIEL, T. Educação aberta: configurando ambientes, práticas e recursos educacionais. São Paulo: Casa da Cultura Digital, 2012, p. 17-33.

BARBOSA, S. D.; SILVA, B. S. Interação humano-computador. Rio de Janeiro: Elsevier, 2010. BRASIL. Lei n. 9.610, de 19 de fev. 1998. Altera, atualiza e consolida a legislação sobre direitos autorais e dá outras providências. Diário Oficial da República Federativa do Brasil, Brasília, v.1, n. 36, p. 10-80, 20 fev. 1998. Seção 1. 
BRASIL. Lei Ordinária n. 13005 de 25 de jun. 2014. Aprova o Plano Nacional de Educação - PNE e dá outras providências. Diário Oficial da República Federativa do Brasil, Brasília, edição extra, jun. 2014. Seção 1.

CÂMARA DOS DEPUTADOS. Plano de Lei n. 1513 de 02 de jun. 2011. Altera dispositivos da Lei $\mathrm{n}^{\circ}$ 9.610, de 1998. Brasília. Relator: Paulo Teixeira (PT/SP). Despacho, n. 2.789/2015, set. 2015.

CHAMMAS, A.; QUARESMA, M.; MONT'ALVÃO, C. Metodologia para criação de aplicativos: uma análise com foco no design centrado no usuário. Anais. Congresso Internacional de Ergonomia e Usabilidade, Design de Interface e Interação Humana - Computador, 14. Joinville: USIHC Ergo Design, 2014. Disponível em: <http://www.leui.dad.pucrio.br/arquivosartigos/chammas_quaresma_montalvao_usihc_2014. pdf>. Acessado em 13 ago. 2018.

DOWNES, S. Learning networks and connective knowledge. 16 out 2008. [S.1: s.n.]. Disponível em:< http://it.coe.uga.edu/itforum/paper92/paper92.html>. Acesso em 13 ago. 2018.

. New technology supporting informal learning. Journal of Emerging Technologies in Web Intelligence, v. 2, n. 1, p. 27-33, 2010.

DUARTE, Fernanda; SANTANA, Ana E. REA: entenda o que são recursos educacionais abertos. Portal EBC, 2015. Disponível em: <http://www.ebc.com.br/educacao/2015/09/rea-entendao-que-sao-os-recursos-educacionais-abertos>. Acesso em 13 ago. 2018.

ERTHAL, C. D. A avaliação dos processos educativos. Santa Rosa: Unijuí, 2015.

INUZUKA, M. A.; DUARTE, R. T. Produção de REA apoiada por MOOC. São Paulo: Casa da Cultura digital, 2012.

KOP, R.; HILL, A. Connectivism: learning theory of the future or vestige of the past? The International Review of Research in Open and Distance Learning, [S.1.], 2008. v. 9, n. 3. Disponível em: http://www.irrodl.org/index.php/irrodl/article/view/523/1103. Acesso em: 13 ago. 2018.

LITTO, F.; MATTAR, J. (Org.). Educação aberta online: pesquisar, remixar e compartilhar. São Paulo: Artesanato Educacional, 2017.

LIYOSHI, T.; KUMAR, M. S. Educação aberta: o avanço coletivo da educação pela tecnologia, conteúdo e conhecimentos abertos. Centro de Recursos Educacionais, 2015. Disponível em: <http://www.abed.org.br/arquivos/Livro_Educacao_Aberta_ABED_Positivo_Vijay.pdf $>$. Acesso em: 13 de ago. 2018.

MATTAR, J. Aprendizagem em ambientes virtuais: teorias, conectivismo e MOOCs. São Paulo: TECCOGS-PUC/SP, v. 7, p. 21-40, 2013.

PESCE, L. A potência didática dos recursos educacionais abertos para a docência na contemporaneidade. Revista Eletrônica de Educação, v. 7, n. 2, p. 195-210, 2013.

PRENSKY, M. Nativos digitais, imigrantes digitais. Rapid City (EUA): NCB University Press, v. 9, n. 5, 2001. Disponível em: <http://www.colegiongeracao.com.br/novageracao/2_intencoes/nativos.pdf $>$. Acesso em: 13 ago. 2018.

REBELO, F. Ergonomia no dia a dia. 2 ed. Portugal: Silabo, 2017.

RIBEIRO, H. S. et al. Integração de tecnologias para desenvolvimento de sistemas web, utilizando a metodologia AJAX. Anais: III SEGET - Simpósio de Excelência em Gestão e Tecnologia, 2006.

Disponível

em: 
<https://www.aedb.br/seget/arquivos/artigos06/304_Artigo_SEGET.pdf>. Acesso em: 13 ago. 2018.

SANTANA, B.; ROSSINI, C.; PRETTO, N. L. (Org.). Recursos educacionais abertos: práticas colaborativas políticas públicas. Salvador: Edufba; São Paulo: Casa da Cultura Digital, 2012.

SANTOS, A. I. Educação aberta: histórico, práticas e o contexto dos recursos educacionais abertos. São Paulo: Casa da Cultura Digital, 2012.

SEBRIAM, D.; MARKUN, P.; GONSALES, P. Como implementar uma política de educação aberta e de recursos educacionais abertos. São Paulo: Cereja, 2017.

SEIXAS, C. A.; MENDES, I. A. E-Learning e educação à distância: guia prático para implementação e uso de sistemas abertos. São Paulo: Atlas, 2006.

SIEMENS, G. Connectivism: a learning theory for the digital age. International Journal of Instructional Technology and Distance Learning, vol. 2, n. 1, p. 3-10, 2005.

. Learning and knowing in networks: changing roles for educators and designers. 27 jan 2008.

[S.l: s.n.]. Disponível em: 〈http://it.coe.uga.edu/itforum/Paper105/Siemens.pdf >. Acesso em 13 de ago. 2018.

SILVA, J.; NUNES, S.; PINTO, A.; BRAGA, M. Recursos Educacionais Abertos e : diálogos pertinentes via um guia de recomendações. Anais: Conferência Ibérica de Sistemas e Tecnologia de Informação, 12. Lisboa, 2017. Disponível em: < https://ieeexplore.ieee.org/document/7975790/>. Acesso em 13 de ago. 2018.

SPYER, J. Conectado: o que a internet fez com você e o que você pode fazer com ela. 2. ed. Rio de Janeiro: Zahar, 2011.

WILEY, D. The access compromise and the 5th $R$. Disponível em: <https://opencontent.org/blog/archives/322>. Acesso em 12 de ago. 2018. 